\title{
Hematologia e bioquímica sérica de equinos de concurso completo de equitação em treinamento
}

\author{
[Hematology and serum biochemistry of event horses in training] \\ J.M. Santiago ${ }^{1}$, F.Q. Almeida ${ }^{2}$, L.L.F. Silva ${ }^{2}$, A.C.T. Miranda ${ }^{2}$, J.F. Azevedo ${ }^{2}$, \\ C.A.A. Oliveira ${ }^{2}$, S.S. Carrilho ${ }^{2}$ \\ ${ }^{1}$ Aluno de pós-graduação - Universidade Federal Rural do Rio de Janeiro - Seropédica, RJ \\ ${ }^{2}$ Instituto de Veterinária - Universidade Federal Rural do Rio de Janeiro - Seropédica, RJ
}

\begin{abstract}
RESUMO
Avaliaram-se a hematologia e a bioquímica sérica em equinos de concurso completo de equitação (CCE) em treinamento durante testes de esforço incremental em esteira ergométrica de alta velocidade. Foram utilizados 16 equinos em delineamento experimental inteiramente ao acaso com quatro tratamentos e quatro repetições em esquema de parcelas subdivididas, utilizando-se como fontes de variação nos tratamentos a idade e o histórico de treinamento em CCE. As parcelas foram constituídas pelos testes incrementais realizados nas fases inicial e final do treinamento. As subparcelas foram representadas pelos tempos de avaliação e coletas. Os equinos do grupo experimental novos iniciantes apresentaram valor médio do hematócrito de 43,24\%, sendo inferior ao hematócrito do grupo adultos iniciantes, 45,63\%, novos experientes, 46,39\%, e competidores, $47,74 \%$. Houve diferença $(\mathrm{P}<0,05)$ entre os testes físicos realizados nas fases inicial e final do treinamento, com redução na concentração plasmática de glicose, de 112 para 98,88mg/dL, nas concentrações séricas de creatinina, de 1,41 para 1,29mg/dL, e de proteínas totais, de 6,52 para 6,38g/dL, na contagem de monócitos, de 0,54 para $0,4810^{3} / \mathrm{mm}^{3}$, e com aumento na concentração plasmática de lactato, de 3,31 para $3,79 \mathrm{mmol} / \mathrm{L}$, na concentração sérica de ácido úrico, de 1,44 para $1,77 \mathrm{mg} / \mathrm{dL}$, no hematócrito, de 44,19 para 46,90\%, na concentração de hemoglobina, de 14,33 para 15,10g/dL, e na contagem de leucócitos totais, de 9,26 para 9,61 $10^{3} / \mathrm{mm}^{3}$. O treinamento dos equinos de CCE aumentou o condicionamento físico dos equinos, com maior capacidade de metabolização do lactato após o exercício e aumento nos valores basais do hematócrito e da concentração de hemoglobina.
\end{abstract}

Palavras-chave: equino, hemograma, leucograma, teste incremental

\begin{abstract}
Was evaluated the hematology and serum biochemistry in event horses (CCE) in training during incremental treadmill tests. Sixteen horses were used in a completely randomized design with four treatments and four repetitions in subdivided parcels, using age and previous history of training in events as sources of treatment variation. The parcels constituted of incremental treadmill tests performed at the beginning and end of training. The subparcels were represented by the time of evaluation and collection of samples. The equines of new beginners group had mean hematocrit value of 43.24\%, being lower than the hematocrit of adult beginners group, 45.63\%, new experienced group, 46.39\%, and competitors group, 47.74\%. There were differences $(P<0.05)$ between the tests performed at the beginning and end of training, with reduction in glucose plasma concentration, from 112 to $98,88 \mathrm{mg} / \mathrm{dL}$, in seric concentration of creatinine, 1.41 to $1.29 \mathrm{mg} / \mathrm{dL}$, and total protein, 6.52 to $6.38 \mathrm{~g} / \mathrm{dL}$, in monocyte count, 0.54 to $0.4810^{3} / \mathrm{mm}^{3}$, and an increase of lactate plasma concentration, from 3.31 to $3.79 \mathrm{mmol} / \mathrm{L}$, in seric concentration of uric acid, 44 to $1.77 \mathrm{mg} / \mathrm{dL}$, in hematocrit, 44.19 to $46.90 \%$, in hemoglobin concentration, 14.33 to $15.10 \mathrm{~g} / \mathrm{dL}$, and blood cell count, 9.26 to $9.6110^{3} / \mathrm{mm}^{3}$. The training of event horses improves physical performance of horses, with increased capacity of lactate metabolism after exercise and increased basal hematocrit and hemoglobin concentration.
\end{abstract}

Keywords: equine, incremental test, hemogram, leukogram

Recebido em 3 de outubro de 2011

Aceito em 1 de outubro de 2012

E-mail:jmartinssantiago@yahoo.com.br 


\section{INTRODUÇÃO}

O conhecimento sobre a forma de utilização de energia em diferentes atividades esportivas possibilita a adoção de estratégias específicas de treinamento, visando à maximização das adaptações em vários sistemas do organismo (Rose e Hodgson, 1994). Segundo Evans et al. (2002), o baixo desempenho de equinos atletas pode estar muitas vezes relacionado à limitação fisiológica na produção de energia para o trabalho muscular. A glicose é uma importante fonte de energia para a atividade muscular, entretanto, com o aumento na intensidade do exercício, grande parte da energia é gerada via glicólise anaeróbia, com consequente produção de ácido láctico (Eaton, 1994).

De acordo com Lindner (2000), a concentração plasmática de lactato apresenta forte correlação com o desempenho esportivo dos equinos, sendo um dos parâmetros mais utilizados para determinar a intensidade dos exercícios de treinamento e para monitorar o condicionamento físico de equinos em treinamento (Ferraz et al., 2008). Semelhante ao lactato, a concentração plasmática do ácido úrico é um bom indicador da intensidade do exercício, pois ele provém da degradação de adenosina difosfato, quando este se acumula na célula por aumento da hidrólise de adenosina trifosfato (ATP), para obtenção de energia durante exercícios de alta intensidade (Castejón et al., 2007).

Em equinos, durante e após exercícios máximos e submáximos, observa-se aumento na concentração plasmática das proteínas totais, albumina, concentração de hemoglobina e contagem total de leucócitos, como resultado da contração esplênica, troca de fluidos intercompartimentais e sudorese (Hargreaves et al., 1999). Após o treinamento, também se observa aumento do hematócrito, sendo mais visível em equinos que passaram por um significativo período sem treinamento (McGowan, 2008). Embora o leucograma não seja utilizado para avaliação do condicionamento físico dos equinos, alterações no número de leucócitos podem indicar doenças subclínicas ou estresse, justificando seu monitoramento (McGowan, 2008). Em equinos sem condicionamento físico adequado, a rotina de exercícios afeta negativamente a função fagocítica dos macrófagos alveolares e a função neutrofílica (Bayly e Kline, 2007).

Este estudo teve como objetivo a avaliação hematológica e da bioquímica sérica de equinos de concurso completo de equitação em treinamento, em testes de esforço incremental em esteira ergométrica de alta velocidade.

\section{MATERIAL E MÉTODOS}

O ensaio foi realizado no Laboratório de Avaliação do Desempenho de Equinos LADEq/UFRRJ, na Escola de Equitação do Exército, Rio de Janeiro. Foram utilizados 16 equinos da raça Brasileiro de Hipismo, na faixa etária entre cinco e 17 anos, machos castrados e fêmeas, com peso corporal entre 420 e $541 \mathrm{~kg}$, utilizados na disciplina de concurso completo de equitação, competindo na categoria Preliminar.

O delineamento experimental foi inteiramente ao acaso com quatro tratamentos - grupos experimentais - e quatro repetições - animais em esquema de parcelas subdivididas, utilizandose como fontes de variação nos tratamentos a idade e o histórico anterior de treinamento em CCE. As parcelas foram constituídas pelos testes incrementais, realizados em esteira ergométrica de alta velocidade, nas fases inicial (teste I) e final do treinamento (teste II), e as subparcelas representadas pelos tempos de avaliação e coletas de amostras em cada teste. Os equinos foram distribuídos em grupos experimentais (tratamentos). O grupo novos iniciantes (tratamento I) foi formado por equinos com idade entre cinco e sete anos, que, no ano anterior ao presente estudo, foram utilizados na disciplina de Iniciação Esportiva da EsEqEx; o grupo adultos iniciantes (tratamento II), constituído por equinos com idade entre 12 e 17 anos, com treinamento anterior na modalidade Salto; o grupo novos experientes (tratamento III), formado por equinos com idade entre cinco e oito anos, com treinamento anterior na modalidade CCE; e o grupo competidores (tratamento IV), constituído por equinos com idade entre oito e 10 anos, competidores na modalidade CCE nos anos anteriores.

Os equinos foram alimentados com dieta composta por $4,0 \mathrm{~kg}$ de feno de coastcross (Cynodon dactylon), fornecido duas vezes ao dia, $6,0 \mathrm{~kg}$ de concentrado comercial, fornecido três 
vezes ao dia e $50 \mathrm{~g}$ de sal mineral, fornecido uma vez ao dia, e livre acesso à água. O concentrado foi fornecido em quantidades iguais às cinco, 16 e 20 horas, e o feno fornecido em quantidades iguais, às 11 e 16 horas.

O treinamento ocorreu no período compreendido entre os meses de fevereiro e novembro. Os animais foram treinados seis dias por semana, de segunda a sábado, no período da manhã, com duração média diária de 50 minutos. Nos meses de abril e maio, os equinos foram adaptados ao exercício em esteira ergométrica de alta velocidade. O primeiro teste para avaliação da fase inicial do treinamento (teste I) ocorreu na primeira semana do mês de junho, correspondente ao início do segundo período de preparação física. O segundo teste para avaliação da fase final do treinamento (teste II) ocorreu no início de outubro, correspondente à fase final do terceiro período de preparação física.

Os testes em esteira de alta velocidade Galloper $\left(\right.$ Sahinco $^{\circledR}$ ) foram conduzidos segundo protocolo adaptado de Rose e Hodgson (1994). O protocolo consistiu de um período de aquecimento de três minutos ao passo, na velocidade de $1,7 \mathrm{~m} / \mathrm{s}$ e $5 \mathrm{~min}$ ao trote $(4,0 \mathrm{~m} / \mathrm{s})$. Em seguida, iniciou-se o exercício progressivo, em que a velocidade foi aumentada em $1 \mathrm{~m} / \mathrm{s}$ a cada minuto, sendo utilizadas as velocidades de $6,7,8,9$ e $10 \mathrm{~m} / \mathrm{s}$. A recuperação foi realizada com 15 minutos ao passo $(1,7 \mathrm{~m} / \mathrm{s})$. Finalizado o teste, os animais foram conduzidos à área externa do laboratório, para um período adicional de $15 \mathrm{~min}$ de recuperação ao passo. Durante os testes, a esteira foi utilizada na inclinação de $4^{\circ}$.

No dia dos testes, as amostras sanguíneas basais foram coletadas às quatro horas, utilizando-se agulhas para coleta a vácuo $\left(\mathrm{BD}^{\circledR}\right)$ e tubos a vácuo com EDTA (Vacutainer BD $^{\circledR}$ ) para avaliação do hemograma. Amostras coletadas em tubos a vácuo com fluoreto de sódio (Vacutainer $\mathrm{BD}^{\circledR}$ ) foram utilizadas para determinação das concentrações plasmáticas de glicose e lactato, e em tubos a vácuo sem anticoagulante (Vacutainer BD $^{\circledR}$ ) para obtenção do soro sanguíneo. Nos testes, as coletas sanguíneas foram feitas por meio do sistema cateter e tubo extensor, nos $15 \mathrm{~s}$ finais de cada minuto de galope e aos 15 e 30min do período de recuperação. As coletas sanguíneas uma e duas horas após os testes foram realizadas utilizando- se agulhas para coleta em tubos a vácuo com EDTA, tubos a vácuo com fluoreto de sódio e tubos a vácuo sem anticoagulante.

As amostras sanguíneas foram centrifugadas a 3000 rotações por minuto por 10 minutos para separação do plasma ou soro. Em seguida, alíquotas de $1 \mathrm{~mL}$ de plasma ou soro foram armazenadas em tubos de polipropileno tipo eppendorf a $-18^{\circ} \mathrm{C}$, para posteriores análises. As análises das concentrações plasmáticas de glicose e lactato e das concentrações séricas de ácido úrico, proteínas totais, albumina, ureia e creatinina foram realizadas utilizando-se kits reagentes (Biosystem $^{\circledR}$ ) em espectofotômetro BTS 315 (Biosystem $^{\circledR}$ ). O hemograma e o leucograma foram realizados em contator automático de células ABC-VET (HoribaABX ${ }^{\circledR}$ ).

$\mathrm{Na}$ avaliação das variáveis bioquímicas e hematológicas, foram utilizados os resultados obtidos com os animais em repouso, nos galopes nas velocidades de 6,7 e $8 \mathrm{~m} / \mathrm{s}$ e durante o período de recuperação. Os resultados das variáveis glicose, lactato, ácido úrico, creatinina e leucócitos totais não apresentaram distribuição normal e homocedasticidade entre os tratamentos e foram submetidos à transformação logarítmica. Os resultados das variáveis albumina e linfócitos não apresentaram distribuição normal e homocedasticidade entre os tratamentos e foram submetidos à transformação radicial. Os resultados foram submetidos à análise de variância em esquema de parcelas subdivididas, sendo as médias comparadas pelo teste Tukey a 5\% de probabilidade, utilizando-se o Programa de Análises Estatísticas e Planejamento de Experimentos SISVAR (versão 5.0).

\section{RESULTADOS E DISCUSSÃO}

Houve diferença $(\mathrm{P}<0,05)$ na concentração plasmática de glicose dos equinos entre as fases inicial (teste I) e final do treinamento (teste II), com menores valores observados no teste II em todos os tempos avaliados (Tab. 1). As menores concentrações de glicose no teste II podem estar relacionadas ao aumento da eficiência na geração e utilização de energia por meio da $\beta$-oxidação dos ácidos graxos em função do treinamento, retardando, consequentemente, a depleção dos estoques de glicogênio muscular e hepático e o tempo para fadiga (Nutrient..., 2007). 
Tabela 1. Concentrações plasmáticas de glicose e lactato nos equinos de concurso completo de equitação nas fases inicial (teste I) e final do treinamento (teste II) e coeficientes de variação (CV) (n=16)

\begin{tabular}{|c|c|c|c|c|c|c|c|c|c|}
\hline \multirow[b]{2}{*}{ Teste } & \multirow[b]{2}{*}{ Repouso } & \multicolumn{3}{|c|}{ Galopes $(\mathrm{m} / \mathrm{s})$} & \multicolumn{4}{|c|}{ Recuperação (min) } & \multirow{2}{*}{$\begin{array}{l}\mathrm{CV} \\
(\%)\end{array}$} \\
\hline & & 6,0 & 7,0 & 8,0 & 15 & 30 & 60 & 120 & \\
\hline \multicolumn{10}{|c|}{ Glicose $(\mathrm{mg} / \mathrm{dL})$} \\
\hline I & $116 \mathrm{Aa}$ & $104 \mathrm{Ab}$ & $108 \mathrm{Ab}$ & $100 \mathrm{Ab}$ & $120 \mathrm{Aa}$ & $122 \mathrm{Aa}$ & $113 \mathrm{Aa}$ & $113 \mathrm{Aa}$ & 14.8 \\
\hline II & $100 \mathrm{Ba}$ & $93 \mathrm{Bb}$ & $92 \mathrm{Bb}$ & $91 \mathrm{Bb}$ & $109 \mathrm{Ba}$ & $105 \mathrm{Ba}$ & $98 \mathrm{Ba}$ & $103 \mathrm{Ba}$ & \\
\hline \multicolumn{10}{|c|}{ Lactato $(\mathrm{mmol} / \mathrm{L})$} \\
\hline I & $0,79 \mathrm{Ae}$ & $3,02 \mathrm{Ac}$ & $5,70 \mathrm{Aab}$ & $8,05 \mathrm{Aa}$ & $3,79 \mathrm{Bbc}$ & 2,10 Acd & $1,66 \mathrm{Ad}$ & 1,39Ade & 57.5 \\
\hline II & $0,54 \mathrm{Ad}$ & $2,03 \mathrm{Ac}$ & 4,62Aab & 7,51Aa & $8,64 \mathrm{Aa}$ & $4,41 \mathrm{Ab}$ & $1,82 \mathrm{Ac}$ & $0,76 \mathrm{Ad}$ & \\
\hline
\end{tabular}

Médias nas colunas, seguidas por letras maiúsculas distintas, diferem entre os testes I e II pelo teste Tukey $(\mathrm{P}<0,05)$. Médias nas linhas, seguidas por letras minúsculas distintas, diferem entre os tempos avaliados pelo teste Tukey $(\mathrm{P}<0,05)$.

Em ambos os testes, as concentrações de glicose dos equinos apresentaram menores valores durante os galopes, havendo aumento no período de recuperação. Resultados semelhantes foram observados por Gill et al. (1987) em equinos de CCE e por Davie e Evans (2000) em equinos da raça Puro Sangue Inglês (PSI).

Segundo Pösö et al. (2004), alterações na concentração de glicose dependem do tipo de exercício. A concentração de glicose tende a diminuir durante exercício prolongado, entretanto, durante exercícios de curta duração, ambos, aumento e diminuição, têm sido observados. No início do exercício, a glicose e o glicogênio muscular são as principais fontes de energia para a contração muscular, sendo observada redução da glicose sanguínea na fase inicial do trabalho. Em seguida, a concentração de glicose sanguínea tende a aumentar, devido à maior glicogenólise e gliconeogênese (Gill et al., 1987).

Não houve diferença $(\mathrm{P}>0,05)$ na concentração plasmática de lactato dos equinos durante a etapa de galopes entre os testes (Tab. 1). A redução na concentração plasmática de lactato nos equinos após o treinamento foi observada por vários estudos que utilizaram equinos de diferentes raças e modalidades hípicas: Evans et al. (1995), ao avaliarem diferentes intensidades de treinamento de equinos PSI; Gehlen et al. (2006), ao compararem equinos de CCE treinados e destreinados; Ferraz et al. (2008), ao avaliarem o treinamento aeróbico de equinos árabes; e Bronsart et al. (2009), ao compararem o treinamento convencional e intervalado de PSI.
Quando equinos são submetidos a protocolos efetivos de treinamento, importantes adaptações fisiológicas levam ao aumento na geração de energia pela via aeróbia (Poole e Erickson, 2008).

De acordo com Evans et al. (1995), durante as primeiras semanas de treinamento, observa-se redução do lactato após exercícios submáximos, entretanto a redução torna-se menos intensa com o progresso do treinamento. No presente estudo, o primeiro teste foi realizado três meses após o início do treinamento, correspondendo à fase inicial do segundo período de preparação física. Embora a primeira fase de preparação física tenha sido caracterizada por exercícios de menor intensidade, adaptações fisiológicas ocorridas nesse período podem ter influenciado na semelhança das concentrações plasmáticas de lactato dos equinos durante a etapa de galopes entre os testes.

Em ambos os testes, na etapa de galopes, a concentração plasmática de lactato dos equinos acompanhou o aumento na intensidade do exercício, atingindo valores máximos a $8,0 \mathrm{~m} / \mathrm{s}$. Entretanto, no teste II, observou-se concentração máxima de lactato também aos 15 minutos de recuperação. No teste I, os equinos de ambos os grupos experimentais realizaram, em média, três minutos de galope, percorrendo $2820 \mathrm{~m}$. No teste II, os equinos realizaram, em média, cinco minutos de galope, percorrendo $3960 \mathrm{~m}$. Segundo Evans et al. (2002), em equinos submetidos a exercícios de intensidade máxima, observa-se o pico da concentração de lactato nos minutos iniciais do período de recuperação. 
Portanto, a semelhança nas concentrações de lactato dos equinos no galope a $8 \mathrm{~m} / \mathrm{s}$ e aos 15 minutos de recuperação no teste II pode estar relacionada à maior distância percorrida, o que resultou em maior produção de lactato devido à maior demanda energética necessária ao maior esforço.

Em ambos os testes, as concentrações de lactato dos equinos retornaram aos valores de repouso duas horas após os exercícios. De acordo com Evans et al. (1995), assim como as concentrações máximas de lactato observadas após testes físicos, o tempo de retorno do lactato aos valores basais também é utilizado em estudos que avaliam o efeito do treinamento sobre o condicionamento físico de equinos. Falaschini e Trombetta (2001) afirmaram que, após exercícios intensos, o tempo de retorno da concentração de lactato de equinos aos valores de repouso pode ser utilizado para avaliar a capacidade de recuperação e utilização do lactato como substrato para as atividades cardíaca e muscular. Embora os equinos no teste II tenham produzido maior concentração de lactato devido à maior distância percorrida, o tempo de retorno do lactato ao valor de repouso foi semelhante entre os testes, o que pode indicar efeito positivo do treinamento sobre o condicionamento fisico dos animais.

Houve diferença $(\mathrm{P}<0,05)$ na concentração sérica de ácido úrico nos equinos entre os testes, com maiores valores observados no teste II (Tab. 2). Segundo Snow et al. (1982), o aumento do ácido úrico após exercícios máximos é menos intenso com o treinamento. Evans et al. (2002) observaram maior concentração de ácido úrico após o exercício em equinos com histórico de baixo desempenho. Entretanto, neste estudo, a maior distância percorrida pelos equinos no teste II pode ter sido responsável pelas maiores concentrações de ácido úrico no segundo teste físico.

Em ambos os testes, observaram-se concentrações máximas de ácido úrico entre 15 e 120 minutos após o exercício. Concentrações máximas de ácido úrico entre 15 e 30 minutos após o exercício foram observadas em equinos de enduro (Snow et al., 1982; Castejón et al., 2006) e em equinos de corrida (Pösö et al., 1993; Räsänen et al., 1996; Evans et al., 2002). Como resultado da degradação do ATP durante o exercício, metabólitos provenientes da degradação dos nucleotídeos derivados da purina, tais como amônia, hipoxantina, ácido úrico e alantoína, aparecem no sangue (Castejón et al., 2006). Nos equinos, há predomínio do ácido úrico e da alantoína como metabólitos finais do catabolismo de purina, com suas concentrações máximas observadas 30 minutos após o exercício (Pösö et al., 2004). Räsänen et al. (1996) observaram que o aumento na concentração de ácido úrico nos equinos ocorre quando a concentração de lactato excede $12 \mathrm{mmol} / \mathrm{L}$, demonstrando que ambos os parâmetros bioquímicos apresentam correlação com o metabolismo anaeróbio (Evans et al., 2002).

Tabela 2. Concentrações séricas de ácido úrico, creatinina e ureia nos equinos de concurso completo de equitação durante as fases inicial (teste I) e final do treinamento (teste II) e coeficientes de variação (CV) $(\mathrm{n}=16)$

\begin{tabular}{|c|c|c|c|c|c|c|c|c|c|}
\hline \multirow[b]{2}{*}{ Teste } & \multirow[b]{2}{*}{ Repouso } & \multicolumn{3}{|c|}{ Galopes $(\mathrm{m} / \mathrm{s})$} & \multicolumn{4}{|c|}{ Recuperação (min) } & \multirow{2}{*}{$\begin{array}{l}\mathrm{CV} \\
(\%)\end{array}$} \\
\hline & & 6,0 & 7,0 & 8,0 & 15 & 30 & 60 & 120 & \\
\hline \multicolumn{10}{|c|}{ Ácido úrico (mg/dL) } \\
\hline I & $1,38 \mathrm{Bb}$ & $1,43 \mathrm{Bb}$ & $1,40 \mathrm{Bb}$ & $1,36 \mathrm{Bb}$ & $1,48 \mathrm{Ba}$ & $1,50 \mathrm{Ba}$ & $1,45 \mathrm{Bab}$ & $1,48 \mathrm{Bab}$ & \multirow{2}{*}{10,2} \\
\hline II & $1,64 \mathrm{Ab}$ & $1,68 \mathrm{Ab}$ & $1,66 \mathrm{Ab}$ & $1,72 \mathrm{Ab}$ & $1,94 \mathrm{Aa}$ & $1,99 \mathrm{Aa}$ & $1,81 \mathrm{Aab}$ & $1,75 \mathrm{Aab}$ & \\
\hline \multicolumn{10}{|c|}{ Creatinina (mg/dL) } \\
\hline I & $1,24 \mathrm{Ad}$ & $1,34 \mathrm{Ac}$ & $1,42 \mathrm{Abc}$ & $1,45 \mathrm{Aab}$ & $1,47 \mathrm{Aa}$ & $1,51 \mathrm{Aa}$ & $1,46 \mathrm{Aab}$ & $1,38 \mathrm{Ac}$ & \multirow{2}{*}{5,2} \\
\hline II & $1,16 \mathrm{Bd}$ & $1,26 \mathrm{Bc}$ & $1,29 \mathrm{Bbc}$ & $1,32 \mathrm{Bab}$ & $1,37 \mathrm{Ba}$ & $1,35 \mathrm{Ba}$ & $1,31 \mathrm{Bab}$ & $1,23 \mathrm{Bc}$ & \\
\hline \multicolumn{10}{|c|}{ Ureia (mg/dL) } \\
\hline $\mathrm{I}$ & 37,7 & 37,0 & 38,1 & 38,5 & 38,2 & 37,9 & 37,6 & 37,0 & \multirow{2}{*}{7,0} \\
\hline II & 35,1 & 35,0 & 36,1 & 35,8 & 35,5 & 35,9 & 36,1 & 36,4 & \\
\hline
\end{tabular}

Médias nas colunas, seguidas por letras maiúsculas distintas, diferem entre os testes I e II pelo teste Tukey $(\mathrm{P}<0,05)$. Médias nas linhas, seguidas por letras minúsculas distintas, diferem entre os tempos avaliados pelo teste Tukey $(\mathrm{P}<0,05)$. 
Houve diferença $(\mathrm{P}<0,05)$ nas concentrações séricas de creatinina nos equinos entre os testes, com maiores valores registrados no teste I (Tab. 2). A concentração de creatinina foi semelhante em ambos os testes, com aumento durante o galope e valores máximos observados nos 60 minutos iniciais de recuperação. O aumento na concentração de creatinina pode estar relacionado à maior utilização de fosfocreatina na geração de energia para a contração muscular na fase inicial do treinamento (Snow et al., 1982). Entretanto, Castejón et al. (2006) observaram que, durante o exercício, ocorre aumento dos níveis plasmáticos de creatinina diretamente proporcional à intensidade do exercício realizado, estando esse aumento relacionado à mudança no fluxo sanguíneo renal. Valores plasmáticos de creatinina acima de $3 \mathrm{mg} / \mathrm{dL}$ indicam falha renal e estão associados a certo grau de desidratação (Castejón et al., 2007). Neste estudo, observaram-se valores médios de creatinina nos equinos de $1,34 \mathrm{mg} / \mathrm{dL}$, portanto dentro da faixa de normalidade.
Não houve diferença $(\mathrm{P}>0,05)$ nas concentrações séricas de ureia nos equinos entre os testes e entre os tempos avaliados, com valor médio de 36,8mg/dL (Tab. 2). Pösö et al. (1993), ao avaliarem equinos de corrida, e Godoi et al. (2010), ao estudarem equinos CCE, também não observaram diferença na concentração de ureia nos equinos antes e após o exercício, com valores médios de $108 \mathrm{mg} / \mathrm{dL}$ e $34,2 \mathrm{mg} / \mathrm{dL}$, respectivamente. A semelhança entre os testes nos valores da concentração de ureia dos equinos pode estar associada ao tipo de exercício realizado, com predomínio da via glicolítica e anaeróbia para geração de energia, em detrimento do catabolismo proteico para suprimento energético observado em provas de resistência (Snow et al., 1982).

Não houve diferença $(\mathrm{P}>0,05)$ na concentração sérica de albumina nos equinos entre os testes, entretanto observou-se diferença $(\mathrm{P}<0,05)$ na concentração sérica das proteínas totais nos equinos em galope a $7 \mathrm{~m} / \mathrm{s}$, com maiores valores no teste I (Tab. 3).

Tabela 3. Concentrações séricas de proteínas totais e albumina nos equinos de concurso completo de equitação durante as fases inicial (teste I) e final do treinamento (teste II) e coeficientes de variação (CV) $(\mathrm{n}=16)$

\begin{tabular}{|c|c|c|c|c|c|c|c|c|c|}
\hline \multirow[b]{2}{*}{ Teste } & \multirow[b]{2}{*}{ Repouso } & \multicolumn{3}{|c|}{ Galopes $(\mathrm{m} / \mathrm{s})$} & \multicolumn{4}{|c|}{ Recuperação (min) } & \multirow{2}{*}{$\begin{array}{l}\mathrm{CV} \\
(\%)\end{array}$} \\
\hline & & 6,0 & 7,0 & 8,0 & 15 & 30 & 60 & 120 & \\
\hline \multicolumn{10}{|c|}{ Proteínas totais $(\mathrm{g} / \mathrm{dL})$} \\
\hline I & $6,25 \mathrm{Ac}$ & $6,75 \mathrm{Aab}$ & $6,91 \mathrm{Aa}$ & $6,80 \mathrm{Aab}$ & $6,28 \mathrm{Ac}$ & $6,37 \mathrm{Ac}$ & 6,49Aabc & $6,27 \mathrm{Ac}$ & \multirow{3}{*}{4,6} \\
\hline II & 5,99Ad & 6,49Aabc & $6,62 \mathrm{Bab}$ & $6,80 \mathrm{Aa}$ & $6,43 \mathrm{Abc}$ & 6,17Acd & 6,24 Acd & 6,26Acd & \\
\hline \multicolumn{9}{|c|}{ Albumina (g/L) } & \\
\hline I & $21,3 \mathrm{c}$ & $23,0 \mathrm{abc}$ & $23,5 \mathrm{ab}$ & $24,0 \mathrm{a}$ & $22,5 \mathrm{abc}$ & $21,4 b c$ & $22,3 a b c$ & $21,7 b c$ & \multirow{2}{*}{8,9} \\
\hline II & $20,0 \mathrm{c}$ & $22,1 \mathrm{ab}$ & $23,6 a$ & $23,9 \mathrm{a}$ & $23,0 \mathrm{ab}$ & $23,5 \mathrm{a}$ & $21,1 \mathrm{bc}$ & $22,7 \mathrm{ab}$ & \\
\hline
\end{tabular}

Médias nas colunas, seguidas por letras maiúsculas distintas, diferem entre os testes I e II pelo teste Tukey $(\mathrm{P}<0,05)$. Médias nas linhas, seguidas por letras minúsculas distintas, diferem entre os tempos avaliados pelo teste Tukey $(\mathrm{P}<0,05)$.

Segundo Bayly e Kline (2007), as concentrações das proteínas totais alteram-se como consequência do treinamento e do exercício, podendo ocorrer leve redução nessas concentrações durante os primeiros dois meses de treinamento. Neste estudo, as concentrações séricas de albumina e proteínas totais aumentaram durante os galopes, atingindo valores máximos a $8 \mathrm{~m} / \mathrm{s}$, e reduziram no período de recuperação. Segundo Kingston (2004), durante o exercício máximo, a redistribuição de fluidos e eletrólitos do compartimento vascular para os espaços extracelulares promove aumento nas concentrações de albumina e proteínas totais, aumentando a viscosidade do plasma. A extensão do deslocamento e da perda de fluidos parece estar relacionada com a duração e a intensidade do exercício, retornando aos valores basais até 30 minutos após o esforço (Kowal et al., 2006). De acordo com Bayly e Kline (2007), em equinos de corrida é comum o aumento de $15 \%$ das proteínas totais após as corridas e nos equinos de enduro há aumento máximo de $25 \%$ durante o exercício, sendo essas alterações relacionadas principalmente à grande perda de líquidos corporais pelo suor. 
Houve diferença $(\mathrm{P}<0,05)$ no hematócrito dos equinos entre os grupos experimentais, com menores valores observados nos equinos do grupo novos iniciantes, de 43,3\%, em relação aos equinos dos grupos adultos iniciantes, novos experientes e competidores de 45,5; 46,4 e $47,7 \%$, respectivamente (Tab. 4). Segundo
Kingston (2004), o hematócrito pode variar com a idade, a raça e o nível de condicionamento. Entre dois e nove anos, observa-se rápida redução do hematócrito e aumento da concentração de hemoglobina em equinos PSI em treinamento (McGowan, 2008).

Tabela 4. Hematócrito dos equinos de concurso completo de equitação dos grupos experimentais novos iniciantes (I), adultos iniciantes (II), novos experientes (III) e competidores (IV) durante as fases inicial (teste I) e final do treinamento (teste II) e coeficientes de variação (CV) $(n=16)$

\begin{tabular}{|c|c|c|c|c|c|c|c|c|c|}
\hline \multirow{2}{*}{ Grupo } & \multirow[b]{2}{*}{ Repouso } & \multicolumn{3}{|c|}{ Galopes $(\mathrm{m} / \mathrm{s})$} & \multicolumn{4}{|c|}{ Recuperação (min) } & \multirow{2}{*}{$\begin{array}{l}\mathrm{CV} \\
(\%)\end{array}$} \\
\hline & & 6,0 & 7,0 & 8,0 & 15 & 30 & 60 & 120 & \\
\hline \multicolumn{10}{|c|}{ Hematócrito (\%) - Teste I } \\
\hline I & $33,3 \mathrm{Be}$ & $48,3 \mathrm{Bb}$ & $52,1 \mathrm{Ba}$ & $50,8 \mathrm{Ba}$ & $41,3 \mathrm{Bc}$ & $36,5 \mathrm{Bd}$ & 34,7Bde & $33,8 \mathrm{Be}$ & \\
\hline II & $33,6 \mathrm{ABe}$ & $49,4 \mathrm{ABb}$ & $55,4 \mathrm{ABa}$ & $57,3 \mathrm{ABa}$ & $43,7 \mathrm{ABc}$ & $37,9 \mathrm{ABd}$ & $37,5 \mathrm{ABde}$ & $36,7 \mathrm{ABe}$ & \\
\hline III & $36,4 \mathrm{ABe}$ & $51,9 \mathrm{ABb}$ & $54,2 \mathrm{ABa}$ & $56,7 \mathrm{ABa}$ & $46,6 \mathrm{ABc}$ & $40,6 \mathrm{ABd}$ & $38,5 \mathrm{ABde}$ & $37,5 \mathrm{ABe}$ & \\
\hline IV & $37,6 \mathrm{Ae}$ & $55,3 \mathrm{Ab}$ & $57,7 \mathrm{Aa}$ & $60,3 \mathrm{Aa}$ & $49,8 \mathrm{Ac}$ & 43,7Ad & 40,3Ade & $37,7 \mathrm{Ae}$ & \\
\hline \multicolumn{9}{|c|}{ Hematócrito (\%) - Teste II } & 4 \\
\hline I & $37,2 \mathrm{Bd}$ & $52,3 \mathrm{Bb}$ & $54,0 \mathrm{Bab}$ & $55,2 \mathrm{Ba}$ & $46,5 \mathrm{Bc}$ & $40,0 \mathrm{Bd}$ & $38,2 \mathrm{Bd}$ & $37,6 \mathrm{Bd}$ & \\
\hline II & $41,0 \mathrm{ABd}$ & $52,5 \mathrm{ABb}$ & $54,5 \mathrm{ABab}$ & $56,5 \mathrm{ABa}$ & $50,5 \mathrm{ABc}$ & $43,3 \mathrm{ABd}$ & $40,4 \mathrm{ABd}$ & $39,9 \mathrm{ABd}$ & \\
\hline III & $38,8 \mathrm{ABd}$ & $53,8 \mathrm{ABb}$ & $56,3 \mathrm{ABab}$ & $58,2 \mathrm{ABa}$ & $49,1 \mathrm{ABc}$ & $42,5 \mathrm{ABd}$ & $40,1 \mathrm{ABd}$ & $41,0 \mathrm{ABd}$ & \\
\hline IV & $39,7 \mathrm{Ad}$ & $53,1 \mathrm{Ab}$ & $54,7 \mathrm{Aab}$ & $58,5 \mathrm{Aa}$ & $49,6 \mathrm{Ac}$ & $41,3 \mathrm{Ad}$ & $40,8 \mathrm{Ad}$ & 43,7Ad & \\
\hline
\end{tabular}

Médias nas colunas, seguidas por letras maiúsculas distintas, diferem entre os grupos pelo teste Tukey $(\mathrm{P}<0,05)$. Médias nas linhas, seguidas por letras minúsculas distintas, diferem entre os tempos avaliados pelo teste Tukey $(\mathrm{P}<0,05)$.

Entretanto, resultado contrário foi observado neste estudo, com aumento da idade e aumento do hematócrito. Provavelmente, os programas de treinamento aos quais os equinos dos grupos adultos iniciantes, novos experientes e competidores foram submetidos nos anos anteriores sejam responsáveis pelos maiores valores do hematócrito. No ano anterior, os equinos do grupo novos iniciantes foram utilizados na disciplina de Iniciação Esportiva, na qual a doma, submissão e determinação das aptidões físicas são os principais objetivos, sendo o condicionamento físico pouco explorado.

Após o treinamento, os equinos apresentaram aumento nos valores basais do hematócrito e da concentração de hemoglobina (Tab. 5). TylerMcGowan et al. (1999) observaram aumento do hematócrito de repouso entre a primeira e sétima semanas de treinamento, e não observaram maiores alterações da sétima à $32^{\mathrm{a}}$ semana. Godoi et al. (2010) observaram aumento somente na concentração de hemoglobina em equinos de CCE submetidos a 82 dias de treinamento. Segundo Kingston (2004) e Castejón et al. (2007), o aumento do hematócrito e da concentração de hemoglobina após o treinamento está relacionado ao aumento da eritropoiese devido à maior produção de eritropoetina, como consequência da hipoxia tecidual à qual a musculatura esquelética é submetida periodicamente durante o treinamento.

Tabela 5. Concentração de hemoglobina nos equinos de concurso completo de equitação durante as fases inicial (teste I) e final do treinamento (teste II) e coeficiente de variação (CV) (n=16)

\begin{tabular}{|c|c|c|c|c|c|c|c|c|c|}
\hline \multirow{2}{*}{ Teste } & \multirow[b]{2}{*}{ Repouso } & \multicolumn{3}{|c|}{ Galopes (m/s) } & \multicolumn{4}{|c|}{ Recuperação (min) } & \multirow{2}{*}{$\begin{array}{l}\mathrm{CV} \\
(\%)\end{array}$} \\
\hline & & 6,0 & 7,0 & 8,0 & 15 & 30 & 60 & 120 & \\
\hline \multicolumn{10}{|c|}{ Hemoglobina (g/dL) } \\
\hline I & $11,2 \mathrm{Be}$ & $16,7 \mathrm{Bb}$ & $17,1 \mathrm{Bab}$ & $18,0 \mathrm{Ba}$ & $14,7 \mathrm{Bc}$ & $12,4 \mathrm{Bd}$ & $12,5 \mathrm{Bde}$ & $12,0 \mathrm{Bde}$ & 9,5 \\
\hline II & $12,5 \mathrm{Ae}$ & $17,0 \mathrm{Ab}$ & $17,6 \mathrm{Aab}$ & $18,3 \mathrm{Aa}$ & $15,6 \mathrm{Ac}$ & $13,7 \mathrm{Ad}$ & 13,0 Ade & 13,1Ade & \\
\hline
\end{tabular}

Médias nas colunas, seguidas por letras maiúsculas distintas, diferem entre os testes pelo teste Tukey $(\mathrm{P}<0,05)$. Médias nas linhas, seguidas por letras minúsculas distintas, diferem entre os tempos avaliados pelo teste Tukey $(\mathrm{P}<0,05)$. 
Os aumentos do hematócrito e da concentração de hemoglobina dos equinos observados no presente estudo, indicam efeito positivo do treinamento sobre o condicionamento físico dos animais, ao potencializar o suprimento de oxigênio para a musculatura esquelética no exercício. No teste II foram registrados maiores valores do hematócrito somente 15 e 120 minutos após o exercício, em relação ao teste I. A concentração de hemoglobina nos equinos no teste II foi superior ao do teste I, em todos os tempos avaliados. Segundo Harkins et al. (1990), o fluxo sanguíneo no baço durante o período de recuperação é maior em equinos treinados, possibilitando maior remoção dos metabólitos gerados no exercício intenso.

Em ambos os testes houve aumento do hematócrito e da concentração de hemoglobina nos galopes, atingindo aumento de 34,2\% no hematócrito e de $34,3 \%$ na concentração de hemoglobina a $8 \mathrm{~m} / \mathrm{s}$, em relação aos valores basais. Resultados semelhantes foram observados por estudos utilizando equinos de diferentes raças e modalidades hípicas (Snow et al., 1982; Kowal et al., 2006; Castejón et al., 2007). Segundo Babusci e López (2007), a contração esplênica eleva o hematócrito de 32 a $42 \%$ no repouso para valores de 60 a $70 \%$ e a concentração de hemoglobina de $15 \mathrm{~g} / \mathrm{dL}$ para $22 \mathrm{~g} / \mathrm{dL}$. Um dos fatores responsáveis pelo aumento do hematócrito durante exercício é a esplenocontração. $\mathrm{O}$ baço tem a capacidade de armazenar cerca de $50 \%$ do volume de eritrócitos do organismo. A liberação desses eritrócitos na corrente sanguínea ocorre como resposta ao estímulo simpático ou ao aumento da adrenalina circulante (Kingston, 2004; McGowan, 2008).

Em relação às alterações leucocitárias devido ao treinamento dos equinos de CCE, observou-se que o número de leucócitos totais dos equinos no teste II foi superior ao teste I somente duas horas após o exercício (Tab. 6).

Tabela 6. Leucócitos totais, granulócitos, monócitos e linfócitos nos equinos de concurso completo de equitação nas fases inicial (teste I) e final do treinamento (teste II) e coeficientes de variação (CV) $(n=16)$

\begin{tabular}{|c|c|c|c|c|c|c|c|c|c|}
\hline \multirow[b]{2}{*}{ Teste } & \multirow[b]{2}{*}{ Repouso } & \multicolumn{3}{|c|}{ Galopes $(\mathrm{m} / \mathrm{s})$} & \multicolumn{4}{|c|}{ Recuperação (min) } & \multirow{2}{*}{$\begin{array}{l}\text { CV } \\
(\%)\end{array}$} \\
\hline & & 6,0 & 7,0 & 8,0 & 15 & 30 & 60 & 120 & \\
\hline \multicolumn{10}{|c|}{ Leucócitos totais $\left(10^{3} / \mathrm{mm}^{3}\right)$} \\
\hline I & 7,4Ae & $11,5 \mathrm{Ab}$ & $11,0 \mathrm{Aab}$ & $11,3 \mathrm{Aa}$ & $9,3 \mathrm{Ac}$ & $8,2 \mathrm{Ad}$ & 7,8Ade & $7,6 \mathrm{Be}$ & \\
\hline II & $8,1 \mathrm{Ad}$ & $10,8 \mathrm{Ab}$ & $11,2 \mathrm{Aab}$ & $11,5 \mathrm{Aa}$ & $10,0 \mathrm{Ac}$ & 8,6 Ad & $8,3 \mathrm{Ad}$ & $8,4 \mathrm{Ad}$ & 5,4 \\
\hline \multicolumn{10}{|c|}{ Granulócitos $\left(10^{3} / \mathrm{mm}^{3}\right)$} \\
\hline I & $5,04 \mathrm{e}$ & $6,78 \mathrm{a}$ & $6,76 a$ & $6,65 \mathrm{ab}$ & $5,76 \mathrm{~cd}$ & $5,38 \mathrm{de}$ & $5,46 \mathrm{de}$ & $6,12 b c$ & \\
\hline II & $5,76 \mathrm{c}$ & $6,74 b$ & $6,68 b$ & $6,58 b$ & $5,83 \mathrm{c}$ & $5,36 \mathrm{c}$ & $5,44 \mathrm{c}$ & $7,49 \mathrm{a}$ & 9,4 \\
\hline \multicolumn{10}{|c|}{ Monócitos $\left(10^{3} / \mathrm{mm}^{3}\right)$} \\
\hline I & $0,44 \mathrm{Ac}$ & $0,63 \mathrm{Aa}$ & $0,59 \mathrm{Aab}$ & $0,59 \mathrm{Aab}$ & $0,58 \mathrm{Aab}$ & $0,53 \mathrm{Ab}$ & $0,48 \mathrm{Ac}$ & $0,45 \mathrm{Ac}$ & 152 \\
\hline II & $0,41 \mathrm{Bc}$ & $0,53 \mathrm{Ba}$ & $0,53 \mathrm{Bab}$ & $0,53 \mathrm{Bab}$ & $0,51 \mathrm{Bab}$ & $0,49 \mathrm{Bb}$ & $0,42 \mathrm{Bc}$ & $0,39 \mathrm{Bc}$ & 15,2 \\
\hline \multicolumn{10}{|c|}{ Linfócitos $\left(10^{3} / \mathrm{mm}^{3}\right)$} \\
\hline I & $2,26 \mathrm{~b}$ & $3,06 \mathrm{a}$ & $3,14 \mathrm{a}$ & $3,24 \mathrm{a}$ & $3,03 \mathrm{a}$ & $2,96 \mathrm{a}$ & $2,46 b$ & $2,17 \mathrm{c}$ & 41 \\
\hline II & $2,56 \mathrm{~b}$ & $3,33 \mathrm{a}$ & $3,21 \mathrm{a}$ & $3,31 \mathrm{a}$ & $3,28 \mathrm{a}$ & $3,13 a$ & $2,43 b$ & $1,93 \mathrm{c}$ & 4,1 \\
\hline
\end{tabular}

Médias nas colunas, seguidas por letras maiúsculas distintas, diferem entre os testes I e II pelo teste Tukey $(\mathrm{P}<0,05)$. Médias nas linhas, seguidas por letras minúsculas distintas, diferem entre os tempos avaliados pelo teste Tukey $(\mathrm{P}<0,05)$.

O número de monócitos foi maior no teste II em todos os tempos avaliados. Não foram observadas diferenças $(\mathrm{P}>0,05)$ no número de granulócitos e linfócitos entre os testes. No presente estudo, o aumento no número de leucócitos totais, granúlocitos, monócitos e linfócitos foi observado durante os galopes, seguido de redução no período de recuperação em ambos os testes. Na velocidade de $8 \mathrm{~m} / \mathrm{s}$ observou-se aumento de $31,6 \%$ na contagem de leucócitos totais em relação aos valores de repouso, em ambos os testes. Segundo Kowal et al. (2006), o leucograma varia com a intensidade e a duração do exercício, podendo haver aumentos de 10 a $30 \%$. O exercício máximo promove liberação de leucócitos sequestrados pelo baço e provenientes do pool marginal. A linfocitose é transitória no exercício máximo, retornando aos valores de repouso após algumas horas. 


\section{CONCLUSÕES}

O treinamento físico dos equinos de concurso completo de equitação promove aumento do condicionamento físico, com aumento do metabolismo do lactato após o exercício e maiores valores basais do hematócrito e da concentração de hemoglobina.

\section{REFERÊNCIAS}

BABUSCI, M.; LÓPEZ, E.F. Sistema cardiovascular. In: BOFFI, F.M. Fisiologia del Ejercicio em Equinos. 1.ed. Buenos Aires: Inter-Médica, 2007. p.123-132.

BAYLY, W.; KLINE, K.A. Hematología y bioquimica. In: BOFFI, F.M. Fisiologia del Ejercicio em Equinos. 1.ed. Buenos Aires: Inter-Médica, 2007. p.145-151.

BRONSART, L.L.; SIDES, R.H.; BAYLY, W.M. A comparative study of interval and continuous incremental training in Thoroughbreds. Equine Comp. Exerc. Physiol., v.6, p.49-57, 2009.

CASTEJÓN, F.; RUBIO, M.D.; AGÜERA, E.I. et al. Respusta hematológica y plasmática al ejercicio em cinta rodante. In: LÓPEZ, G.E.V. Valoración morfofuncional e la selección de reproductores del Caballo de Pura Raza Española. 1.ed. Córdoba: Caja Rural, 2007. p.169-196.

CASTEJÓN, F.; TRIGO, P.; MUÑOZ, A. et al. Uric acid responses to endurance racing and relationships with performance, plasma biochemistry and metabolic alterations. Equine Vet. J., v.36, suppl., p.70-73, 2006.

DAVIE, A.J.; EVANS D.L. Blood lactate responses to submaximal field exercise tests in Thoroughbred horses. Vet. J., v.159, p.252-258, 2000.

EATON, M.D. Energetics and performance. In: HODGSON, D.R.; ROSE, R.J. The athletic horses: principles and practice of equine sports medicine. 1.ed. Philadelphia: Saunders, 1994. p.49-62.

EVANS, D.L.; PRIDDLE, T.L.; DAVIE, A.J. Plasma lactate and uric acid responses to racing in pacing Standardbreds and relationships with performance. Equine Vet. J., v.34, suppl., p.131-134, 2002.

EVANS, D.L.; RAINGER, J.E.; HODGSON, D.R. et $a l$. The effects of intensity and duration of training on blood lactate concentrations during and after exercise. Equine Vet. J., v.18, suppl., p.422-425, 1995.

FALASCHINI, A.; TROMBETTA, M.F. Modifications induced by training and diet in some exercise-related blood parameters in young trotters. $J$. Equine Vet. Sci., v.21, p.601-604, 2001.
FERRAZ, G.C.; D'ANGELIS, F.H.F.; TEIXEIRANETO, A.R. et al. Blood lactate threshold reflects glucose responses in horses submitted to incremental exercise test. Arq. Bras. Med. Vet. Zootec., v.60, p.256-259, 2008.

GEHLEN, H.; MARNETTE, S.; ROHN, K.; et al. Echocardiographic comparison of left ventricular dimensions and function after standardized treadmill exercise in trained and untrained healthy warmblood horses. Equine Comp. Exerc. Physiol., v.3, p.3-11, 2006.

GILL, J.; JABLONSKA, E.M.; ZIOLKOWSKA, S.M. et al. Influence of differential training on some haematological and metabolic indices in sport horse before and after exercise trials. J. Vet. Med. Educ., v.34, p.609-616, 1987.

GODOI, F.N.; ALMEIDA, F.Q.; MIGON, E.X.F. et al. Performance of eventing horses fed high fat diet. Rev. Bras. Zootec., v.39, p.335-343, 2010.

HARGREAVES, B.J.; KRONFELD, D.S.; NAYLOR, J.R. Ambient temperature and relative humidity influenced packed cell volume, total plasma protein and other variables in horses during an incremental submaximal field exercise test. Equine Vet. J., v.31, p.314-318, 1999.

HARKINS, J.D.; KAMERLING, S.G.; BAGWELL, C.A. et al. A comparative study of interval and conventional training in Thoroughbred racehorses. Equine Vet. J., v.9, suppl., p.14-19, 1990.

KINGSTON, J.K. Hematologic and serum biochemical responses to exercise and training. In: HINCHCLIFF, K.W.; KANEPS, A.J.; GEOR, R.J. Equine Sports Medicine and Surgery. 1.ed. Philadelphia: Saunders, 2004. p.939-948.

KOWAL, R.J.; ALMOSNY, N.R.P.; CASCARDO, B. et al. Avaliação dos valores hematológicos em cavalos (Equus caballus) da raça Puro-Sangue-Inglês (PSI) submetidos a teste de esforço em esteira ergométrica. Rev. Bras. Cienc. Vet., v.13, p.25-31, 2006.

LINDNER, A. Use of blood biochemistry for positive performance diagnosis on sports horses in practice. Rev. Med. Vet-Toulouse, v.151, p.611-618, 2000.

McGOWAN, C. Clinical Pathology in the Racing Horse: The Role of Clinical Pathology in Assesing Fitness and Performance in the Racehorse. Vet. Clin. N. Am: Equine Pract., v.24, p.405-421, 2008.

NUTRIENT requeriments of horses. 6.ed. Washington: National Academy, 2007. 341p.

POOLE, D.C.; ERICKSON, H.H. Cardiovascular function and oxygen transport: responses to exercise and training. In: HINCHCLIFF, K.W.; GEOR, R.J.; KANEPS, A.J. Equine Exercise Physiology. 1.ed. Philadelphia: Saunders, 2008. p.211-245. 
PÖSÖ, A.R.; ESSÉN-GUSTAVSSON, B.; PERSSON, S.G.B. Metabolic response to standardised exercise test in Standardbred trotters with red cell hypervolaemia. Equine Vet. J., v.25, p.527-531, 1993.

PÖSÖ, A.R.; HYYPPÄ, S.; GEOR, R.J. Metabolic responses to exercise and training. In: HINCHCLIFF, K.W.; KANEPS, A.J.; GEOR, R.J. Equine Sports Medicine and Surgery. 1.ed. Philadelphia: Saunders, 2004. p.771-792.

RÄSÄNEN, L.; WIITANEN, P.A.S.; LILIUS, E. et al. Accumulation of uric acid in plasma after repeated bouts of exercise in the horse. Comp. Biochem. Physiol., v.114, p.139-144, 1996.
ROSE, R.J.; HODGSON, D.R. An overview of Performance and Sports Medicine. In: HODGSON, D.R.; ROSE, R.J. The athletic horses: principles and practice of equine sports medicine. 1.ed. Philadelphia: Saunders, 1994. p.3-25.

SNOW, D.H.; KERR, M.; NIMMO, M. et al. Alterations in blood, sweat, urine and muscle composition during prolonged exercise in the horse. Vet. Rec., v.110, p.377-384, 1982.

TYLER-McGOWAN， C.M.; GOLLAND， L.C.; EVANS, D.L. Haematologic and biochemical responses to training and overtraining. Equine Vet. J., v.30, suppl., p.621-625, 1999. 